\title{
Glucagon-like peptide-1 (GLP-1) receptors are not overexpressed in pancreatic islets from patients with severe hyperinsulinaemic hypoglycaemia following gastric bypass
}

\author{
J. C. Reubi • A. Perren • R. Rehmann • B. Waser • \\ E. Christ • M. Callery • A. B. Goldfine • M. E. Patti
}

Received: 11 May 2010 / Accepted: 26 July 2010 /Published online: 14 September 2010

(C) Springer-Verlag 2010

\begin{abstract}
Aims/hypothesis Glucagon-like peptide-1 (GLP-1) receptors are highly overexpressed in benign insulinomas, permitting in vivo tumour visualisation with GLP-1 receptor scanning. The present study sought to evaluate the GLP-1 receptor status in vitro in other pancreatic disorders leading to hyperinsulinaemic hypoglycaemia, specifically after gastric bypass surgery.

Methods Fresh frozen pancreatic tissue samples $(n=7)$ from six gastric bypass surgery patients suffering from hyperinsulinaemic hypoglycaemia were evaluated for
\end{abstract}

J. C. Reubi $(\bowtie) \cdot$ A. Perren $\cdot$ R. Rehmann $\cdot$ B. Waser Division of Cell Biology and Experimental Cancer Research, Institute of Pathology, University of Berne,

PO Box 62, Murtenstrasse 31,

CH-3010 Berne, Switzerland

e-mail: reubi@pathology.unibe.ch

E. Christ

Divisions of Endocrinology, Diabetology, and Clinical Nutrition, Inselspital, University Hospital of Berne,

Berne, Switzerland

\section{Callery}

Department of Surgery,

Beth Israel Deaconess Medical Center,

Boston, MA, USA

\section{A. B. Goldfine $\cdot$ M. E. Patti}

Research Division, Joslin Diabetes Center,

Boston, MA, USA

M. Callery · A. B. Goldfine · M. E. Patti

Harvard Medical School,

Boston, MA, USA
GLP-1 receptor content using in vitro receptor autoradiography, and compared with normal pancreas and with pancreatic insulinoma tissues.

Results GLP-1 receptor analysis of the pancreatic tissues, which histopathologically were compatible with nesidioblastosis and originated from post-bypass hypoglycaemic patients, revealed a mean density value of GLP-1 receptors in the islets of $1,483 \pm 183 \mathrm{dpm} / \mathrm{mg}$ tissue. Pharmacological characterisation indicated the presence of specific GLP-1 receptors. The density of islet GLP-1 receptor in post-gastric bypass patients did not differ from that of normal pancreas $(1,563 \pm 104 \mathrm{dpm} / \mathrm{mg}$ tissue, $n=10)$. Receptor density in pancreatic acini was low in post-bypass and control conditions. In contrast, benign insulinomas showed a high density of GLP-1 receptors, with a mean value of $8,302 \pm 1,073 \mathrm{dpm} / \mathrm{mg}$ tissue $(n=6)$.

Conclusions/interpretation In contrast to insulinoma, hyperinsulinaemic hypoglycaemia after gastric bypass surgery is not accompanied by overexpression of GLP-1 receptor in individual islets. Thus, patients with post-gastric bypass hyperinsulinaemic hypoglycaemia are not candidates for GLP-1 receptor imaging in vivo using radiolabelled exendin. These GLP-1 receptor data support the notion that the islet pathobiology of post-gastric bypass hypoglycaemia is distinctly different from that of benign insulinomas.

Keywords Exendin - Gastric bypass - GLP-1 receptors . Hyperinsulinaemic hypoglycaemia $\cdot$ Nesidioblastosis . Pancreatic islets

Abbreviation

GLP-1 Glucagon-like peptide-1 


\section{Introduction}

Glucagon-like peptide-1 (GLP-1) is an important glucosedependent insulin secretagogue released primarily from the small intestine in response to nutrient intake [1]. GLP-1 effects are mediated by GLP-1 receptors, which have been identified as class 2 G-protein-coupled receptors and are produced in particular in pancreatic islets, intestine, lung and brain [1]. Recently, GLP-1 receptors have been found to be overexpressed at very high density in virtually all tested benign pancreatic insulinomas [2]. Compared with tumours from other organs, insulinomas express by far the highest level of GLP-1 receptors [3]. Based on these observations, a diagnostic method was developed, which permits localisation of benign insulinomas with a scanning method using intravenously injected ${ }^{111}$ In-labelled DOTAexendin-4, a synthetic GLP-1 analogue [4]. The method successfully localises benign insulinomas that remain undetected with established diagnostic methods [5].

The magnitude of GLP-1 receptor production is largely unknown in other pancreatic pathologies linked to excessive insulin secretion. Preliminary in vitro and in vivo data in malignant insulinomas indicate that only a subgroup of tumours express GLP-1 receptors, while the remaining tumours, including primary and metastasis, do not [6]. Another distinct clinical syndrome is that of postprandial hypoglycaemia, typically occurring several years after gastric bypass surgery for obesity [7-10]. In a small subset of individuals, this form of hypoglycaemia is severe and unresponsive to nutritional and medical management, and partial pancreatectomy has been performed for symptom control $[7,9,10]$. While the specific pathogenic mediators of this syndrome remain unclear, food intake in patients with this syndrome results in rapid elevations of plasma glucose, insulin and C-peptide, with subsequent development of hypoglycaemia during the later postprandial period [8]. It remains unclear whether increased insulin secretion in this syndrome is due to: (1) observed increases in secretion of GLP-1, gastric inhibitory polypeptide or other incretins; (2) altered responsiveness to incretins or other insulin secretagogues; or (3) cell-autonomous insulin secretion [7]. In some individuals with this syndrome, diffuse islet cell hyperplasia and expansion of beta cell mass has been observed [9, 10]; in other studies, increased nuclear size relative to body mass, but not hyperplasia has been reported [7]. We hypothesised that GLP-1 receptor production might be increased in pancreases of patients with post-gastric bypass hypoglycaemia, potentially contributing to their enhanced GLP-1 sensitivity and action. In addition, we wished to determine whether GLP-1 receptor levels might permit future GLP-1 receptor-mediated scanning for evaluation of islet mass in this setting.

Thus, in vitro GLP-1 receptor autoradiography, a morphological method that can distinguish the pancreatic cell populations, was used to quantify the GLP-1 receptor content in islet cells and acini. GLP-1 receptor content in post-gastric bypass hypoglycaemia patient samples was compared with pancreas samples obtained from organ donors or from patients undergoing pancreas surgery for benign or malignant tumours, and with insulinoma tumour samples, a reference tissue with extreme GLP-1 receptor overexpression [2].

\section{Methods}

Fresh frozen samples of pancreatic tissues were obtained from surgically resected specimens. Of these samples, seven were from six patients suffering from hyperinsulinaemic hypoglycaemia after gastric bypass surgery and four were normal pancreatic samples obtained at the time of pancreatic surgery for benign or malignant non-endocrine tumours from normoglycaemic patients. Samples were obtained from the Joslin Diabetes Center and Beth Israel Deaconess Medical Center. In addition, six normal pancreatic samples from organ donors or tumour patients and six insulinoma samples were collected at the Institute of Pathology, University of Berne for use as controls. Informed consent was obtained from all patients. The study conformed to the ethical guidelines of the Joslin Diabetes Center, Beth Israel Deaconess Medical Center and the Institute of Pathology, University of Bern, and was carried out in accordance with the principles of the Declaration of Helsinki as revised in 2000.

In vitro GLP-1 receptor autoradiography was performed as described previously [2], using ${ }^{125}$ I-labelled GLP-1(736)amide ( $74 \mathrm{TBq} / \mathrm{mmol}[2,000 \mathrm{Ci} / \mathrm{mmol}]$; Anawa, Wangen, Switzerland) as radioligand. Competition experiments were performed by adding increasing concentrations of the GLP-1 receptor-selective analogue GLP-1(7-36)amide, the GLP-2 receptor-selective analogue GLP-2 (Bachem, Bubendorf, Switzerland) or the glucagon receptor-selective analogue glucagon(1-29) (Bachem). Receptor density in islets and in acini was quantitatively assessed using tissue standards and a computer-assisted image processing system (Analysis Imaging System; InterFocus, Mering, Germany). As a positive control, human insulinomas were used in each procedure [2].

Cryostat sections adjacent to those used for in vitro receptor autoradiography were selected for insulin and synaptophysin immunohistochemistry, in order to identify unambiguously all pancreatic islets, as previously reported [11].

\section{Results}

GLP-1 receptors, assessed by in vitro receptor autoradiography, were present in pancreatic islets and acini of all patient samples examined, with levels in islets about two- 
to threefold higher than in acini, although substantial individual variability in receptor density was observed. In patients with post-gastric bypass hypoglycaemia syndrome, the mean density of GLP-1 receptors was $1,483 \pm$ $183 \mathrm{dpm} / \mathrm{mg}$ in islets and $529 \pm 107$ in acinar tissue, these values being similar to those of controls (Table 1). Figure $1 \mathrm{a}-\mathrm{c}$ shows representative images of a control pancreas, a pancreas from a patient with post-gastric bypass hypoglycaemia and an insulinoma. Upon histopathology, post-gastric bypass hypoglycaemia syndrome samples were characterised by a statistically significantly increased islet size compared with the islets of control patients (Table 1). The number of islets per surface area was higher in bypass patients than in controls but did not reach statistical significance (Table 1). Islets from postgastric bypass hypoglycaemic patients expressed moderate GLP-1 receptor levels (Fig. 1b), while acini were only weakly labelled. Pancreatic islets from controls had similar moderate GLP-1 receptor levels while acini from controls had low receptor levels. In contrast, benign insulinoma tissue had homogeneous and very high levels of GLP-1 receptors, as previously described [2].

To establish whether the receptors detected in postgastric bypass hypoglycaemic patients were specific GLP-1 receptors, pharmacological characterisation was performed in all tissues from this patient group and is illustrated (Fig. 1d) in a competition experiment with one of the patients. GLP-1 receptors in post-gastric bypass patients were found to be of high affinity for GLP-1, with cold GLP-1 displacing radiolabelled GLP-1 at low nanomolar concentrations (Fig. 1d). The receptors were specific for GLP-1, as only the GLP-1 analogue was able to displace the radioligand with high affinity, whereas the GLP-2 analogue or glucagon(1-29) bound only with low

Table 1 Subject characteristics, surgical procedure and pancreatic sample characterisation in post-gastric bypass patients with severe hypoglycaemia requiring partial pancreatectomy, compared with controls

\begin{tabular}{|c|c|c|c|c|c|c|c|c|c|c|}
\hline \multirow[t]{2}{*}{$\begin{array}{l}\text { Sample } \\
\text { number }\end{array}$} & \multicolumn{2}{|c|}{ Demographic } & \multicolumn{2}{|c|}{ BMI $\left(\mathrm{kg} / \mathrm{m}^{2}\right)$} & \multicolumn{2}{|l|}{ Clinical } & \multicolumn{2}{|l|}{ Histopathology } & \multicolumn{2}{|c|}{$\begin{array}{l}\text { GLP-1 receptor } \\
\text { density }(\mathrm{dpm} / \mathrm{mg})\end{array}$} \\
\hline & $\begin{array}{l}\text { Age } \\
\text { (years) }\end{array}$ & Sex & Pre-GB & Post-GB & Glucose $^{\mathrm{a}}$ & $\begin{array}{l}\text { Time to } \\
\text { pancreatectomy }\end{array}$ & Islet size ${ }^{c}$ & $\begin{array}{l}\text { Islet } \\
\text { number }^{\mathrm{d}}\end{array}$ & Islet $^{\mathrm{e}}$ & Acinar ${ }^{\mathrm{e}}$ \\
\hline \multicolumn{11}{|l|}{ Patients } \\
\hline 1 & 28 & F & 46.8 & 26.2 & 2.3 & 1.8 & $0.021 \pm 0.012$ & 2.8 & $1,202 \pm 222$ & $570 \pm 114$ \\
\hline $2^{f}$ & & & & & & & $0.024 \pm 0.016$ & 2.4 & $1,134 \pm 211$ & $245 \pm 61$ \\
\hline 3 & 31 & F & 40.0 & 26.1 & 1.9 & 3.2 & $0.018 \pm 0.010$ & 4.5 & $2,396 \pm 331$ & $1,001 \pm 93$ \\
\hline 4 & 49 & F & 43.5 & 29.7 & 2.2 & 3.0 & $0.016 \pm 0.010$ & 3.1 & $1,002 \pm 124$ & $309 \pm 73$ \\
\hline 5 & 69 & F & 48.4 & 34.0 & 3.2 & 3 & $0.027 \pm 0.016$ & 7.6 & $1,539 \pm 144$ & $784 \pm 89$ \\
\hline 6 & 46 & M & 40.6 & 23.1 & 2.4 & 1.8 & $0.026 \pm 0.018$ & 2.3 & $1,295 \pm 182$ & $280 \pm 90$ \\
\hline 7 & 41 & $\mathrm{~F}$ & 41.3 & 25.1 & 2.9 & 3.8 & $0.013 \pm 0.007$ & 1.5 & $1,814 \pm 127$ & $511 \pm 35$ \\
\hline Mean $^{g}$ & & & & & & & $0.021 \pm 0.002$ & $3.46 \pm 2.05$ & $1,483 \pm 183$ & $529 \pm 107$ \\
\hline \multicolumn{11}{|l|}{ Controls } \\
\hline A & & & & & & & $0.011 \pm 0.002^{\mathrm{h}}$ & $1.98 \pm 0.78^{\mathrm{i}}$ & $1,563 \pm 104$ & $676 \pm 101$ \\
\hline B & & & & & & & & & $8,302 \pm 1,073^{\mathrm{j}}$ & \\
\hline
\end{tabular}

All patients underwent Roux-en-Y gastric bypass (GB).

Control A represents normal pancreas (gender M/F: $5 / 5$; mean age: $48 \pm 6$ years; $n=10$ ). Control B represents benign insulinomas (sex M/F: 2/4; mean age: $50 \pm 5$ years; $n=6$ )

${ }^{\text {a }}$ Postprandial in $\mathrm{mmol} / \mathrm{l}$

${ }^{\mathrm{b}}$ Time (in years) from bypass to pancreatectomy

${ }^{\mathrm{c}}$ Islet size in $\mathrm{mm}^{2}$, mean $\pm \mathrm{SD}$, was quantified for the 50 largest islets in each sample according to Service et al. [9]

${ }^{\mathrm{d}}$ Islet number was quantified in the whole sample area and expressed as islet number per $\mathrm{mm}^{2}$ (islet size $\geq 0.002 \mathrm{~mm}^{2}$ )

${ }^{\mathrm{e}}$ Mean $\pm \mathrm{SEM}$

${ }^{\mathrm{f}}$ Samples 1 and 2 are two separate samples from the same patient

${ }^{\mathrm{g}}$ Of post-bypass patients

${ }^{\mathrm{h}}$ Mean \pm SEM $(n=10)$; control values were significantly different $\left(p<0.005\right.$, unpaired $t$ test) from the bypass patient values $\left(0.021 \pm 0.002 \mathrm{~mm}{ }^{2}\right.$; mean \pm SEM, $n=7$ ).

${ }^{\mathrm{i}}$ Mean \pm SD $(n=10)$; lower but not significantly different $(p>0.05$, unpaired $t$ test) from the mean \pm SD $(n=7)$ of islet numbers in bypass patients $\left(3.46 \pm 2.05\right.$ islets per $\left.\mathrm{mm}^{2}\right)$

${ }^{\mathrm{j}}$ In tumour tissue 


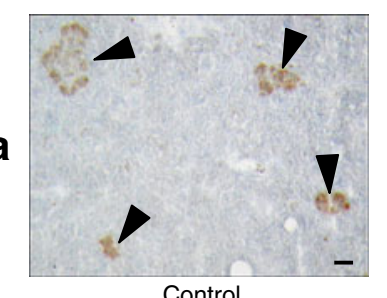

Control
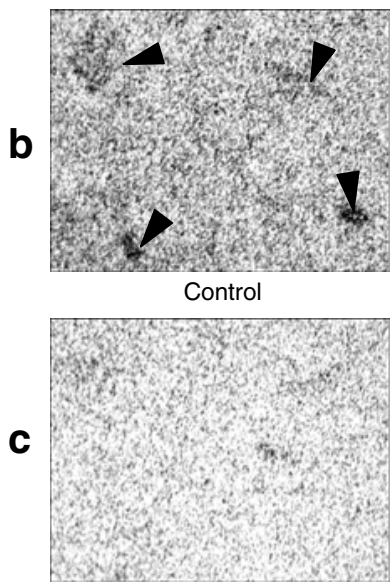

Pancreas

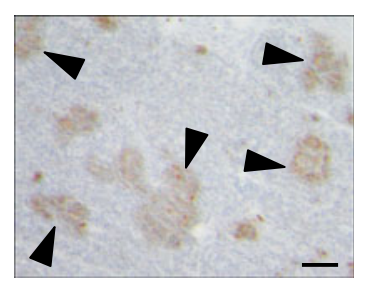

Post-bypass

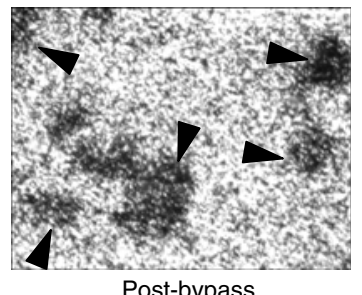

Post-bypass

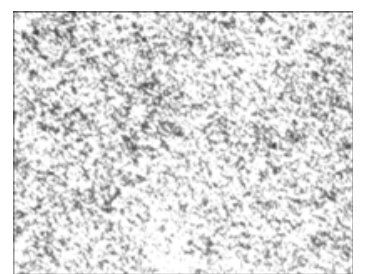

Post-gastric bypass Neuroglycopenia Pancreas

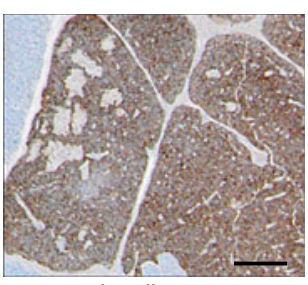

Insulinoma

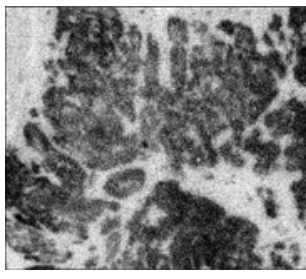

Insulinoma

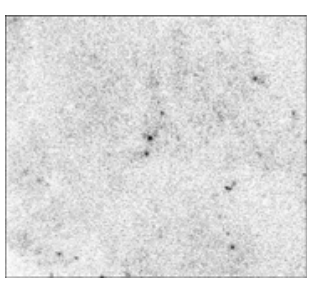

Insulinoma

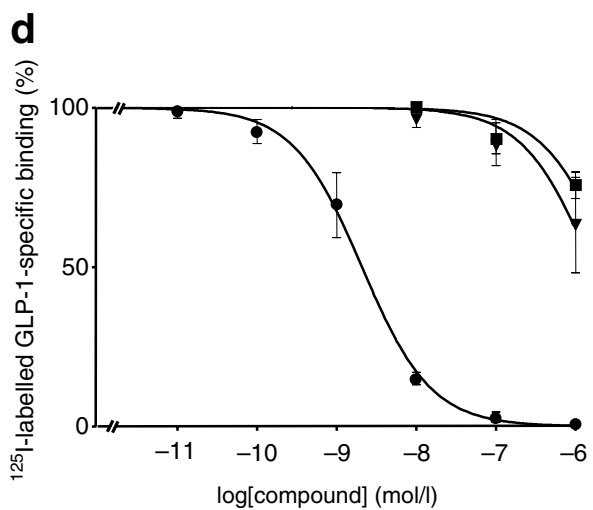

Fig. 1 In vitro receptor autoradiography detection of GLP-1 receptor in pancreatic samples from adult nesidioblastosis compared with normal pancreas and insulinoma. a Insulin immunohistochemistry on cryostat sections of control and post-bypass pancreas. Arrowheads, islets surrounded by acini. Scale bars, $0.1 \mathrm{~mm}$. Insulin immunohistochemistry was also done on paraffin sections of insulinoma tissue. Scale bar, $1 \mathrm{~mm}$. b Autoradiograms showing total binding of ${ }^{125} \mathrm{I}$ labelled GLP-1(7-36)amide, with moderate binding (arrowheads) observed in islets from control and post-bypass samples, and weak binding in acini. Very strong binding was observed in insulinoma

tissue. c Autoradiograms showing non-specific binding of ${ }^{125} \mathrm{I}$ labelled GLP-1(7-36)amide in the presence of $100 \mathrm{nmol} / \mathrm{l}$ unlabelled (cold) GLP-1(7-36)amide. d Competition experiment in pancreatic islet tissue originating from post-bypass patients and showing highaffinity displacement of ${ }^{125}$ I-labelled GLP-1(7-36)amide by GLP-1 receptor-selective agonist GLP-1(7-36)amide (circles), and lowaffinity displacement by GLP-2 receptor-selective agonist GLP-2 (triangles) and glucagon receptor-selective agonist glucagon(1-29) (squares). Values are mean $\pm \mathrm{SEM} ; n=3$

affinity. This rank order of potency of the various analogues is characteristic of and specific to the GLP-1 receptor.

\section{Discussion}

Roux-en-Y gastric bypass is highly successful in reducing body weight, improving metabolic status and normalising hyperglycaemia in patients with type 2 diabetes [12]. One increasingly recognised, albeit uncommon long-term complication of this surgery is hyperinsulinaemic hypoglycaemia. In a very small subset of patients, hypoglycaemia may be very severe and unresponsive to medical and nutritional management; in some cases, partial pancreatectomy has been performed for patient safety [10]. Pancreases from these patients demonstrate islet cell hyperplasia, with enlarged and/or more numerous islets, some of them adjacent to and budding from ducts, consistent with socalled nesidioblastosis [10]. Metabolic studies have demon- strated dysregulation of insulin secretion following oral liquid meals, potentially linked to increased incretin secretion resulting from early nutrient exposure to the intestinal Roux limb [8]. Increased incretin sensitivity could also contribute to the syndrome. Furthermore, insulinoma has also been reported in some individuals following gastric bypass surgery. An important, but unanswered question is whether there are any molecular parallels between insulinoma and the excessive insulin secretion and potential islet cell hyperplasia observed in this subgroup of post-gastric bypass patients.

GLP-1 receptors mediate GLP-1 effects to stimulate insulin secretion [1]. In gastric bypass patients, GLP-1 levels are increased in response to standard liquid meals [8], suggesting a potential role for GLP-1 in mediating insulin secretion and, potentially, islet expansion and/or protection against apoptosis. It was previously unknown whether differences in GLP-1 receptor levels could make an additional contribution to the pathophysiology. Our studies demonstrate that GLP-1 receptor content does not differ in 
islet or acinar tissue in the post-gastric bypass hypoglycaemia setting. Moreover, the normal content of GLP-1 receptors is in sharp contrast to the robust overexpression of GLP-1 receptors in human insulinoma. Our data thus suggest that different pathophysiological mechanisms contribute to increased insulin secretion in these two hyperinsulinaemic hypoglycaemic conditions.

Our results are based on in vitro receptor autoradiography, a method that has a number of advantages [2, 3]. First, morphology permits distinction of islets from acini, which is important as both compartments normally express GLP-1 receptors. Second, autoradiography is quantitative and, in contrast to immunohistochemistry, permits precise evaluation of GLP-1 receptor density in specific compartments [3]. Third, it is a highly specific method that allows assessment of ligand binding through direct pharmacological characterisation of the binding sites.

What, if any, immediate clinical consequences could result from the present study? We had previously considered the possible use of ${ }^{111}$ In-labelled DOTA-exendin-4 for in vivo imaging of post-gastric bypass hypoglycaemia patients, with a view to ruling out insulinoma and assessing possible increases in islet mass. Our results do not support the rationale behind such an approach at the present time, as neither islet nor acinar GLP-1 receptor levels differed in post-gastric bypass patients with hypoglycaemia compared with control pancreas.

Acknowledgements This study was supported by the Juvenile Diabetes Research Foundation and the American Society for Metabolic and Bariatric Surgery.

Duality of interest The authors declare that there is no duality of interest associated with this manuscript.

\section{References}

1. Holst JJ (2007) The physiology of glucagon-like peptide 1 . Physiol Rev 87:1409-1439

2. Reubi JC, Waser B (2003) Concomitant expression of several peptide receptors in neuroendocrine tumors as molecular basis for in vivo multireceptor tumor targeting. Eur J Nucl Med 30:781-793

3. Korner M, Stockli M, Waser B, Reubi JC (2007) GLP-1 receptor expression in human tumors and human normal tissues: potential for in vivo targeting. J Nucl Med 48:736-743

4. Wild D, Mäcke H, Christ E, Gloor B, Reubi JC (2008) Glucagonlike peptide 1-receptor scans to localize occult insulinomas. N Engl J Med 359:766-768

5. Christ E, Wild D, Forrer F et al (2009) Glucagon-like peptide-1 receptor imaging for localization of insulinomas. J Clin Endocrinol Metab 94:4398-4405

6. Christ E, Wild D, Caplin M et al (2010) Glucagon-like peptide-1 compared with somatostatin receptor2 targeting in malignant insulinoma. Endocr Rev 31(Suppl 1):S971 [Abstract]

7. Meier JJ, Butler AE, Galasso R, Butler PC (2006) Hyperinsulinemic hypoglycemia after gastric bypass surgery is not accompanied by islet hyperplasia or increased beta-cell turnover. Diabetes Care 29:1554-1559

8. Goldfine AB, Mun EC, Devine E et al (2007) Patients with neuroglycopenia after gastric bypass surgery have exaggerated incretin and insulin secretory responses to a mixed meal. J Clin Endocrinol Metab 92:4678-4685

9. Service GJ, Thompson GB, Service FJ, Andrews JC, CollazoClavell ML, Lloyd RV (2005) Hyperinsulinemic hypoglycemia with nesidioblastosis after gastric-bypass surgery. N Engl J Med 353:249-254

10. Patti ME, McMahon G, Mun EC et al (2005) Severe hypoglycaemia post-gastric bypass requiring partial pancreatectomy: evidence for inappropriate insulin secretion and pancreatic islet hyperplasia. Diabetologia 48:2236-2240

11. Reubi JC, Kappeler A, Waser B, Laissue JA, Hipkin RW, Schonbrunn A (1998) Immunohistochemical localization of somatostatin receptors sst2A in human tumors. Am J Pathol 153:233-245

12. Goldfine AB, Shoelson SE, Aguirre V (2009) Expansion and contraction: treating diabetes with bariatric surgery. Nat Med $15: 616-617$ 